\title{
Adhesion of Ceramic Coating on Thin and Smooth Metal Substrate: A Novel Approach with a Nanostructured Ceramic Interlayer
}

\author{
R. Vert, P. Carles, E. Laborde, G. Mariaux, E. Meillot, and A. Vardelle
}

(Submitted January 11, 2012; in revised form March 19, 2012)

\begin{abstract}
The adhesion of plasma-sprayed coating is, to a large extent, controlled by the cleanness and roughness of the surface on which the coating is deposited. So, most of the plasma spray procedures involve surface pretreatment by grit-blasting to adapt the roughness of the surface to the size of the impacting particles. This preparation process brings about compressive stresses that make it inappropriate for thin substrates. The present works aim to elaborate a thick ceramic coating (about $0.5 \mathrm{~mm}$ thick) on a thin metal substrate $(1 \mathrm{~mm}$ thick) with a smooth surface (Ra of about $0.4 \mu \mathrm{m}$ ). The coating system is intended for use in a Generation-IV nuclear energy system. It must exhibit a good adhesion between the ceramic topcoat and the smooth metal substrate to meet the specifications of the application. Our approach consisted of depositing the ceramic topcoat by air plasma spraying on a few micrometers thick ceramic layer made by suspension plasma spraying. This nanostructured layer played the role of a bond coat for the topcoat and made it possible to deposit it on the as-received substrate. The adhesion of the nanostructured layer was measured by the Vickers indentation cracking technique and that of the ceramic duplex coating system by tensile test.
\end{abstract}

Keywords adhesive strength, atmospheric plasma spray (APS), nanomaterials, suspension plasma spraying, thermal barrier coatings (TBCs), zirconia

\section{Introduction}

The Generation-IV nuclear energy systems are intended to offer significant advances in the following areas: sustainability, safety and reliability, economics, proliferation resistance, and physical protection. The technology goals involve sustainable energy generation with extension of nuclear fuel supply, minimization and management of nuclear waste, safe and reliable operation with improved accident management, competitive costs and financial risks of nuclear energy systems, control and security of nuclear material and nuclear facilities (Ref 1).

The gas-cooled fast reactor (GFR) system is one of six reactor concepts selected within the Generation-IV International Forum (Ref 1). This high-temperature, fast-neutron reactor maximizes the usefulness of uranium resources

This article is an invited paper based on an oral presentation at the 5th International Workshop on Suspension and Solution Thermal Spraying (S2TS) 2011. This workshop was held in Tours, France, October 3-4, 2011 and was organized by CEA Le Ripault.

R. Vert and E. Meillot, CEA, Monts, France; and P. Carles, E. Laborde, G. Mariaux, and A. Vardelle, University of Limoges, Limoges, France. Contact e-mail: vert.romain@gmail.com. by breeding plutonium and can contribute to minimizing both the quantity and the radiotoxicity of nuclear waste by actinide transmutation in a closed fuel cycle. The heliumcooled reactor operates with an outlet temperature of $850{ }^{\circ} \mathrm{C}$ and uses a direct-cycle, helium turbine for electricity $\left(42 \%\right.$ efficiency at $\left.850{ }^{\circ} \mathrm{C}\right)$ and process heat for thermochemical production of hydrogen (Ref 1,2$)$. Protective coatings are visualized to protect various parts of the system and also protect the system in extreme cases where the functional temperature can increase up to $1250^{\circ} \mathrm{C}$ and there is depressurization from 70 bars to atmospheric pressure. Such coatings must withstand high temperature, depressurization, and specific conditions of wear linked to erosion by high-speed (about $280 \mathrm{~m} / \mathrm{s}$ ) helium gas flow. They would be deposited on materials $1 \mathrm{~mm}$ thick that are resistant to heat and erosion and exhibit stable mechanical properties at high temperatures, e.g. Haynes ${ }^{\circledR} 230$ a solidsolution-strengthened nickel-base alloy.

Ceramic coatings deposited by plasma spraying are potential candidates for the protective coatings. However, both the procedures used to prepare the substrate before deposition and the spray process have to be adapted to the thinness of substrates and its low surface roughness (average roughness, $\mathrm{Ra}$, of $0.4 \mu \mathrm{m}$ ).

The principal objective of surface preparation is to achieve proper adhesion of the thermal spray coating to the substrate. The procedure generally combines abrasive blasting with other surface preparation techniques to create the appropriate degree of surface cleanliness and roughness. However, the roughening of the surface by grit-blasting induces compressive stresses that bring about a deformation of thin substrates, e.g., compressive stresses 
of $400 \mathrm{MPa}$ were measured in $1 \mathrm{~mm}$ thick 304L substrate (Ref 3) after grit-blasting. Thus, this technique could not be put into practice for this application where the shape of the parts to be covered has not to be altered.

Three plasma technologies could be used to deposit the ceramic coating: conventional APS plasma spraying using powder, suspension plasma spraying (SPS), and solution plasma spraying. The latter technique was not considered in this study because, in our experience, it is more sensitive to the spraying conditions than suspension spraying and so could make the industrial application more difficult, or at least longer to develop.

The APS spraying of the $0.5 \mathrm{~mm}$ thick ceramic coating on the as-received substrate after solvent cleaning for removing the potential surface contaminants did not make it possible to form a coating with good adhesion to the substrate whatever the spraying conditions and temperature of the substrate. Also the deposition of a $0.5 \mathrm{~mm}$ thick ceramic coating by suspension spraying had taken a too long time and, so, was barely conceivable for the application.

Therefore, to circumvent this adhesion problem, a specific procedure has to be developed; it consisted of the deposition of a duplex thermal barrier coating made of (i) a thin layer of yttria-stabilized zirconia (YSZ) by SPS on the as-received and cleaned alloy and (ii) a thick layer of YSZ by conventional air plasma spraying (APS). The SPS layer created an increased surface area for the mechanical bonding of the APS coating and provided the adhesion of the duplex coating to the Haynes ${ }^{\circledR} 230$ alloy. No metallic bond coat was used in this study as the Haynes ${ }^{\circledR} 230$ alloy has rather low thermal expansion characteristics $(12 \times$ $10^{-6} / \mathrm{C}$ compared to $10 \times 10^{-6} / \mathrm{C}$ for $\mathrm{YSZ}$ at ambient temperature) and the nanostructured SPS layer should also help to relieve the strain in the coating system (Ref 4). In addition, the system will not operate under oxidizing conditions and a metal bond coat should have to be formed on the smooth substrate surface and would also require a specific substrate surface preparation and spray process to make it adhere to the substrate.

This paper presents the spraying procedure for the duplex coating and its adhesive properties.

\section{Experimental Procedure}

\subsection{Materials}

The YSZ powder $\left(\mathrm{ZrO}_{2}-8\right.$ wt. $\left.\% \mathrm{Y}_{2} \mathrm{O}_{3}\right)$ used for the solid phase of the suspension was supplied by Inframat
Corp. (Willington, CT, USA). It was made via an aqueous chemical synthesis route and the particle size ranged between 30 and $60 \mathrm{~nm}$. The suspension was prepared by mixing the powder with distilled water and, then, by stirring the mixture with mechanical means and ultrasounds to break up the agglomerates. The solid content of the suspension varied from 6 to $20 \mathrm{wt} . \%$. No dispersant was added to the suspension since a sedimentation test showed that the sedimentation time was by far longer than the length of the spraying procedure. The YSZ powder used for APS was supplied by Medicoat AG (Mägenwil, Switzerland); the particle size ranged between 22 and $45 \mu \mathrm{m}$ with a mean diameter of $30 \mu \mathrm{m}$.

Button-shaped Haynes ${ }^{\circledR} 230$ substrates $2.54 \mathrm{~cm}$ in diameter and $0.01 \mathrm{~cm}$ in thickness were used. The weight composition of this alloy was the following: $\mathrm{Ni} 57 \%, \mathrm{Cr}$ $22 \%$, W 14\%, Mo 2\%, and Fe max 3\%. The average surface roughness of the as-manufactured surface was about $0.5 \mu \mathrm{m}$. Prior to coating deposition, the substrates were ultrasonically degreased using acetone and alcohol.

\subsection{Plasma Spray Conditions}

Spraying was carried out with a SulzerMetco F4-VB (Sulzer-Metco AG, Wohlen, Switzerland) with a $6 \mathrm{~mm}$ diameter nozzle. Different sets of plasma conditions were used for the spraying of suspension and powder, which are shown in Table 1.

For SPS, the liquid suspension was fed in the form of a liquid jet from a pressurized reservoir through a $250 \mu \mathrm{m}$ nozzle. The plasma spray conditions and suspension injection conditions were chosen, thanks to a design of experiments (Ref 5, 6), based on mechanical properties of the coating: hardness, Young modulus determined by nanoindentation test. The used combination of plasma spray conditions and suspension injection conditions made it possible to get a break-up of the liquid suspension in the catastrophic regime in the plasma core. The very thin droplets formed from the liquid jet were rapidly swept downstream by the gas flow and, then, heated and accelerated.

For APS, two plasma gas conditions were chosen to obtain either dense or porous coating. The dense coating was deposited with an $\mathrm{Ar}-\mathrm{H}_{2}$ mixture with a specific enthalpy of $20.4 \mathrm{MJ} / \mathrm{kg}$ and the porous one with an $\mathrm{Ar} / \mathrm{He} / \mathrm{H}_{2}$ mixture with a specific enthalpy of $16.2 \mathrm{MJ} / \mathrm{kg}$. The powder carrier gas flow rate was adjusted so that the mean trajectory of particles made an angle of $3^{\circ}$ with the torch axis for both plasma conditions.

Table 1 Plasma spraying parameters

\begin{tabular}{|c|c|c|c|}
\hline Plasma torch & F4-VB Sulzer-Metco & & \\
\hline Anode diameter, mm & 6 & & \\
\hline Spraying process & SPS & APS & \\
\hline Plasma gas & $\mathrm{Ar} / \mathrm{He} / \mathrm{H}_{2}$ & $\mathrm{Ar} / \mathrm{H}_{2}$ & $\mathrm{Ar} / \mathrm{He} / \mathrm{H}_{2}$ \\
\hline Plasma gas flow rate, slim & $45 / 45 / 3$ & $45 / 15$ & $12 / 45 / 3$ \\
\hline Arc current, A & 700 & 600 & \\
\hline Feedstock injection & $\begin{array}{l}\text { Liquid pressure: } 0.45 \mathrm{MPa} \\
\text { Nozzle diameter: } 250 \mu \mathrm{m}\end{array}$ & $\begin{array}{l}\text { Carrier gas flow rate adapted } \\
\text { to plasma conditions }\end{array}$ & \\
\hline Spray distance, $\mathrm{mm}$ & 40 & 100 & \\
\hline Plasma gun traverse speed, $\mathrm{m} / \mathrm{s}$ & 1.5 & & \\
\hline Plasma gun scanning step, mm & 5 & & \\
\hline
\end{tabular}

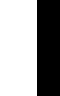


The temperature of coating was controlled during the spray process by $\mathrm{CO}_{2}$ cryogenic cooling to maintain its temperature at the temperature set point. For SPS, the Haynes $^{\circledR}$ substrate was preheated and maintained at $400{ }^{\circ} \mathrm{C}$ and for APS, the substrate covered with the YSZ SPS coating was maintained at $200{ }^{\circ} \mathrm{C}$. These temperatures correspond to the transition temperature of YSZ particles plasma sprayed on Haynes ${ }^{\circledR} 230$ and zirconia surface, respectively. During the preheating and deposition stages, the substrate temperature was monitored by an infra-red pyrometer (Modline 4, Ircon, 8-14 $\mu \mathrm{m}$ wavelength range) and a K-type thermocouple.

\subsection{Coating Characterization}

The objective of this study was to get adherent ceramic coating to the metal substrate. Both the adhesion of the coating system (substrate + SPS layer + APS layer) and that of the SPS bond coat layer were characterized. The former was measured in accordance with the ASTMC-633-799 tensile adhesion test standard (Ref 7) using a universal testing machine (Adamel-Lhomargy DY 26). Samples were glued (Araldite AV 118) to steel cylinders and cured for $90 \mathrm{~min}$ at $175^{\circ} \mathrm{C}$ under $20 \mathrm{~N}$ of applied load. The bond strength was calculated by dividing the pull stress required to fracture the coating by the crosssectional area of the sample. The presented results of tensile bond strength tests represented an average value of five tests.

However, this method turned out to be inappropriate for the SPS coating because of its thickness and porosity. Therefore, the adhesion of the SPS layer was characterized using the Vickers indentation cracking (VIC) test that consisted in indenting the substrate in the cross section and determining the distance $Z_{\text {adh }}$ between the indentation and the interface corresponding to the apparition of crack at interface for a given load, as shown in Fig. 1. According to this method, the coating characterized by the shorter distance between indentation and interface for

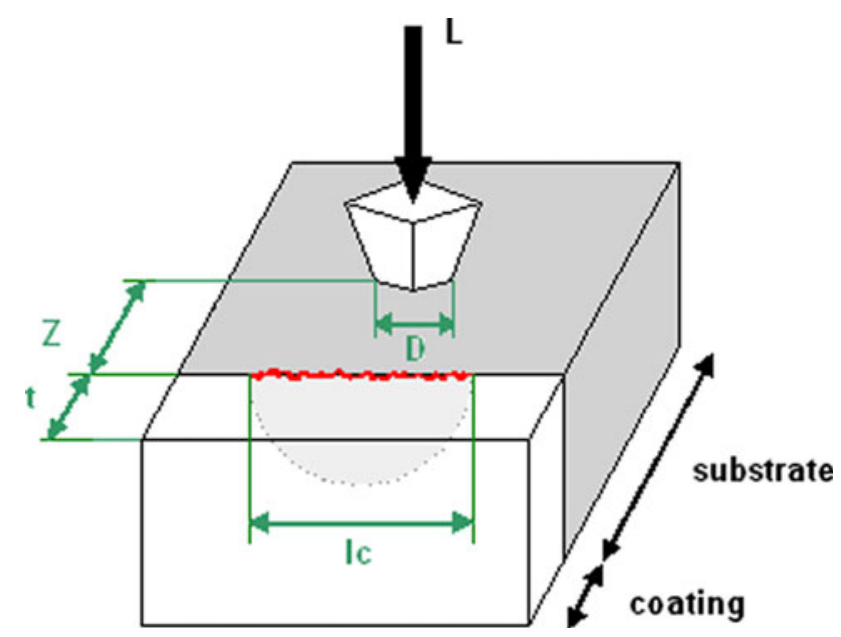

Fig. 1 VIC test. $Z$ is the indentation distance from the interface, $t$ is the coating thickness, $L_{\mathrm{c}}$ is the crack length, and $L$ is the applied load crack generation exhibited the higher adhesion. The application of the VIC test to SPS coating is described in detail in Ref 8.

Microstructures of coatings were observed by scanning electron microscopy (SEM, Phillips XL30 and FEG-SEM, Jeol7400F), either with the secondary electron (SE) or back-scattered electron (BSE) modes. The former enabled a higher resolution than the BSE mode $(50 \mathrm{~nm}$ compared to $100 \mathrm{~nm}$ ) while the latter could enhance the contrast between the various phases present in coatings. Also, the substrate surface before and after preheating was analyzed by x-ray photoelectron spectroscopy (XPS, Kratos Axis Ultra DLD spectrometer) using a monochromatic Al K $\alpha$ source $(10 \mathrm{~mA}, 10 \mathrm{kV})$. All binding energies were referenced to the $\mathrm{C}_{0 \mathrm{~s}}$ peak $(174 \mathrm{eV})$ arising from surface contamination. The use of XPS made it possible to determine the chemical bonding of the main elements present at the surface of the substrate.

\section{Results and Discussions}

\subsection{Coating Microstructures}

Typical microstructures of the YSZ SPS coating and duplex coating produced with the spray parameters summarized in Table 1 are shown in Fig. 2 and 3, respectively.

The open porosity of the APS layer, measured by mercury intrusion technique, was about $11 \%$ for the coating deposited with $\mathrm{Ar}-\mathrm{H}_{2}$ plasma gas and about $22 \%$, for that deposited with Ar-He- $\mathrm{H}_{2}$ plasma gas (Ref 9). The porosity of the SPS layer measured by Ultra Small Angle $\mathrm{x}$-ray scattering and observed by FEG-SEM image analysis was between 12 and $25 \%$ with a pore size ranging between $10 \mathrm{~nm}$ and $1 \mu \mathrm{m}$ (Ref 10).

\subsection{Adhesion of SPS Layer on Metal Substrate}

The first stage of the approach presented in this study consisted of depositing a thin layer $(<100 \mu \mathrm{m})$ of YSZ by SPS with a high adhesion to the substrate. The industrialization of the process required that the coating was deposited on as-manufactured Haynes ${ }^{\circledR}$ sheet with $\mathrm{Ra}$ of $0.4 \mu \mathrm{m}$. However, the key point to make it adherent to

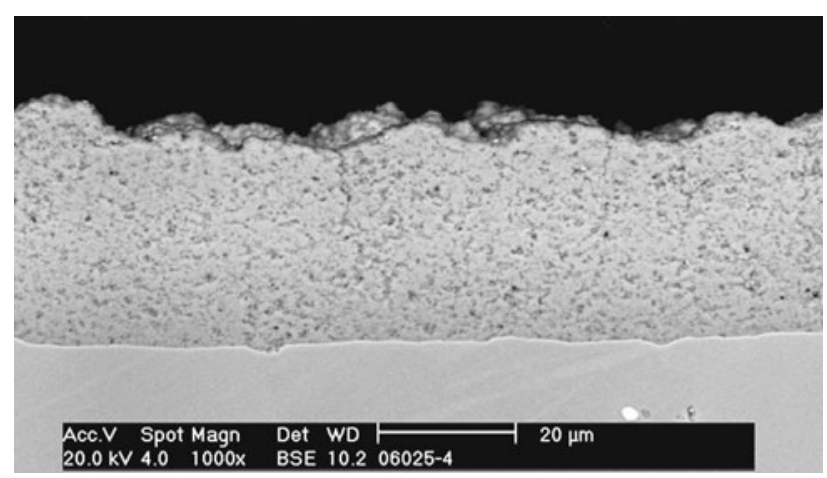

Fig. 2 Microstructure of SPS-YSZ layer. Suspension solid content: 6 wt. $\%$ and $\mathrm{Ar}-\mathrm{He}-\mathrm{H}_{2}$ plasma gas mixture 


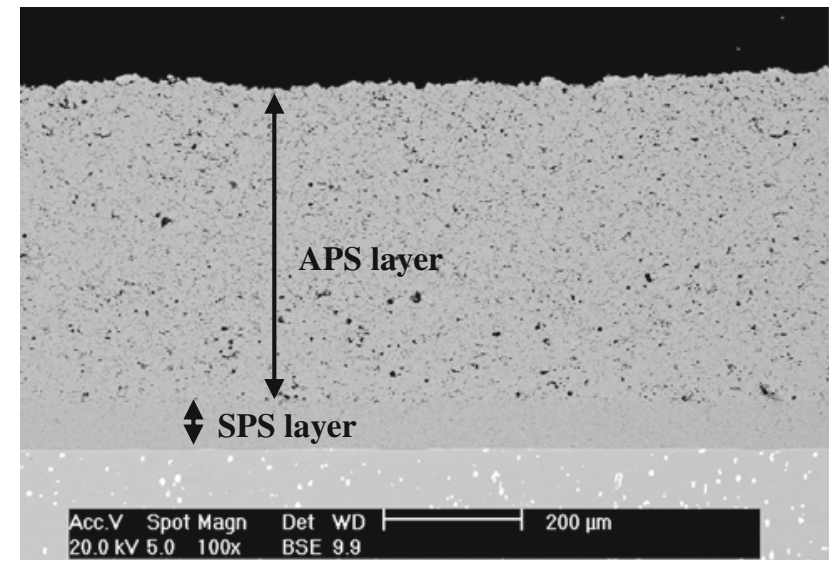

Fig. 3 Microstructure of the YSZ duplex coating. SPS layer: solid content of suspension: 6 wt. $\%$; plasma gas: Ar-He-H ${ }_{2}$; APS layer: $\mathrm{Ar}-\mathrm{H}_{2}$ plasma gas

substrate was the substrate temperature that had to be preheated and maintained at $400{ }^{\circ} \mathrm{C}$ during the spray process. The observation of single splats collected on the substrate (Ref 5) brought out that this temperature corresponded to the transition temperature of YSZ splats on Haynes ${ }^{\circledR} 230$ substrate. However, the question rose on a possible oxidation of the Haynes ${ }^{\circledR}$ substrate at this temperature and, so, XPS measurements were used for investigating the substrate surface chemistry before and after preheating.

Figure 4 shows the XPS profile for the surface of Haynes ${ }^{\circledR}$ substrate before and after preheating at $400{ }^{\circ} \mathrm{C}$. It should be noted that it does not show the complete range of binding energy. In the selected range (840.7 to $870 \mathrm{eV})$, nickel ( $\left.\mathrm{Ni} 2 \mathrm{p}_{3 / 2}\right)$ is observed as main peak on the as-manufactured surface. After heating, Ni peak disappears for oxide and hydroxide peaks (Ref 11, 12).

The same observation can be made for the $\operatorname{Cr}\left(2 \mathrm{p}_{3 / 2}\right)$ peaks that disappeared for chromium oxide peaks after substrate preheating. The XPS analysis also showed the presence of contaminants on the surface before preheating.

The adhesion of the SPS layer when the substrate temperature was at least equal to $400{ }^{\circ} \mathrm{C}$ could be explained both by the desorption of the adsorbates and the presence of oxides at the surface appearing during the preheating stage. The thin oxide should improve the affinity of the oxide droplets with the substrate surface and modify the liquid material wettability during the spreading process (Ref 13, 14).

The FEG-SEM observation of the SPS layer revealed that it exhibited a triple structure: a very thin and dense layer about $20 \mathrm{~nm}$ thick surmounted by another dense layer about $200 \mathrm{~nm}$ thick exhibiting a columnar layer and, finally a granular structure layer (Fig. 5). The first layer was most likely composed of oxides formed by the superficial oxidation of the substrate during the preheating stage with elements coming both from ceramic splats and substrate (Ref 15). The second layer exhibited a columnar structure. It resulted from the piling up of the YSZ splats that are maintained at sufficient high temperatures to grow together while the heat flux was controlled by the

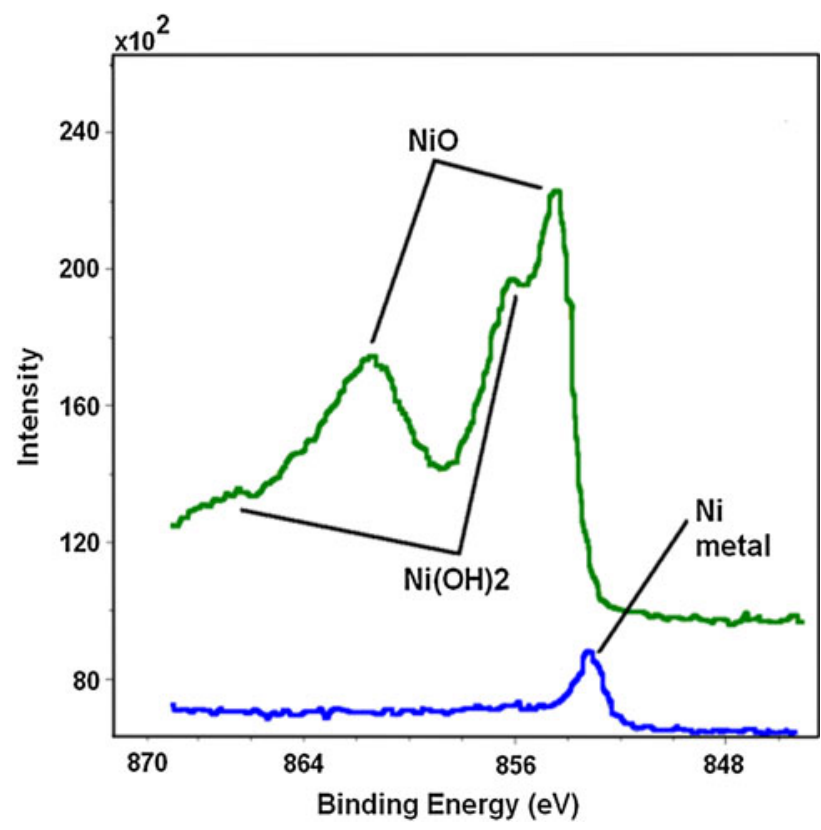

Fig. 4 The change in XPS profile for the surface of as-received Haynes ${ }^{\circledR} 230$ substrate before preheating (blue curve) and after preheating (green curve) at $400{ }^{\circ} \mathrm{C}$ (Color figure online)

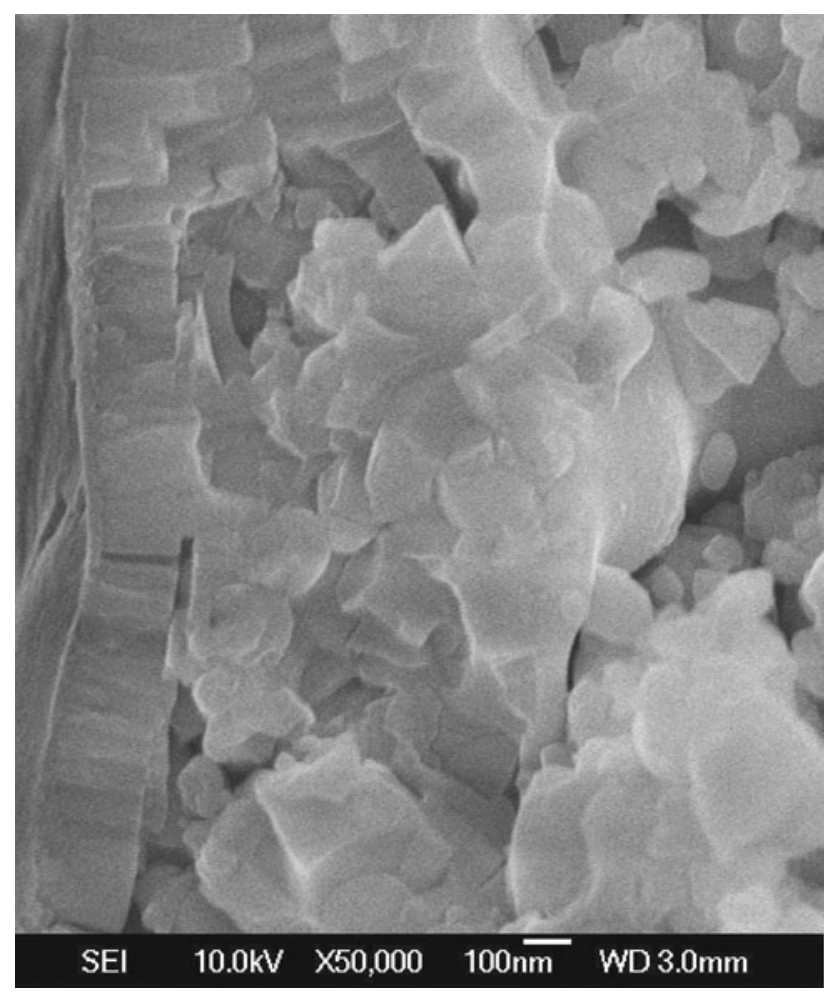

Fig. 5 Fractured section of the bottom of the SPS layer

high-temperature difference between the impacting material and the substrate surface. The thickness of this layer corresponded to 3 to 10 splats. Beyond this thickness, the insulating layer could delay the heat flux to substrate, and thus material solidification. The flattening 

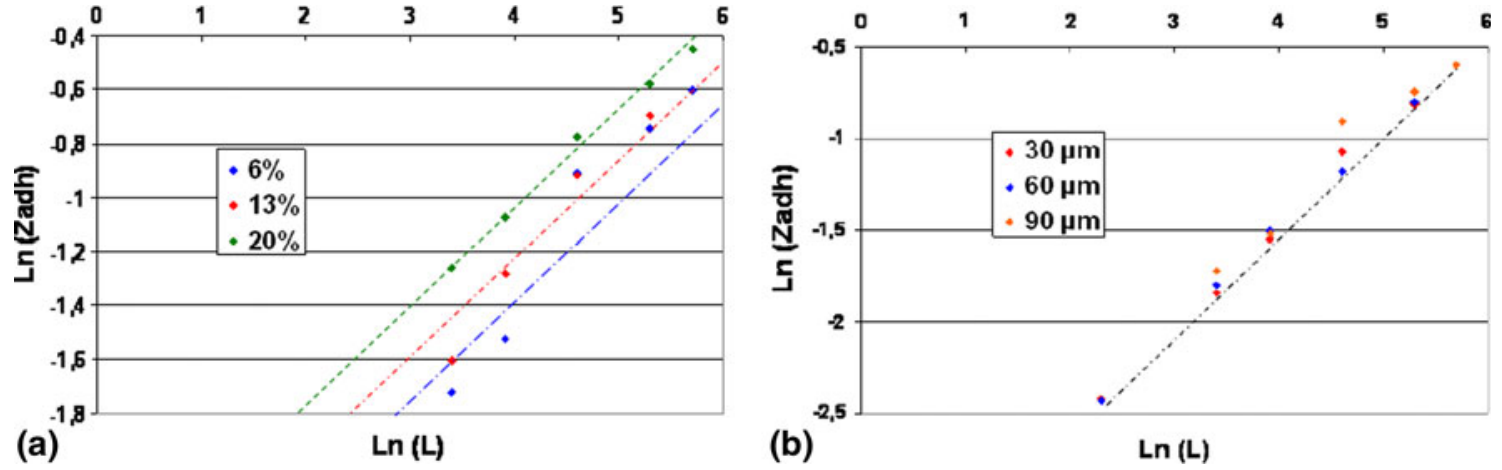

Fig. 6 Adhesive properties of the SPS layer under different manufacturing conditions according to the VIC test: plot of the variation of the natural logarithm function of the distance of the indentation to the coating/substrate interface $Z_{\text {adh }}(\mathrm{mm})$ with the natural logarithm function of the applied load $L(\mathrm{~N})$. $Z_{\text {adh }}$ corresponds to the apparition of crack at interface. (a) Variation with the solid content of suspension (coating thickness: $30 \mu \mathrm{m}$ ). (b) Variation with SPS coating thickness (solid content in suspension: 6 wt.\%)

droplets, between 50 and $300 \mathrm{~nm}$ in diameter, could then undergo recoil prior to solidification. This phenomenon, which is a result of the surface energy of the droplet-solid system, is enhanced by the small size of the impacting droplets $(<\mu \mathrm{m})$ that gives rise to very high surface tension (Ref 16).

The VIC test presented in Fig. 6(a) showed that the adhesion of the SPS layer decreased with the increase of the solid content of the suspension. This can be explained by differences in coating microstructure. Indeed, the FEGSEM pictures revealed an increase in the size of the granular particles constituting the third layer of the SPS coating when increasing the solid content of the suspension. The mean particle size was about 300,400 , and $550 \mathrm{~nm}$ for the coating manufactured with a mass ratio of 6,13 , and 20 wt. $\%$ in the suspension, respectively. This variation came along with a variation in coating porosity that was about $12.0,17.5$, and $22.7 \%$, respectively, and in coating hardness that was about 10,6 , and $5 \mathrm{GPa}$, respectively.

An increase in the mass content of the solution made it possible to increase coating deposition rate but also resulted in an increase in the density of cracks within the coating because of a higher stress level in the layer.

When the mass content of suspension was low (6\%), the thickness of the SPS layer had nearly no effect on its adhesive properties as long as it was $<100 \mu \mathrm{m}$, as shown in Fig. 6(b).

\subsection{Adhesion of the Duplex Coating}

According to the results of the previous study on the adhesive properties of the SPS layer, the topcoat layer made by APS was deposited on SPS layer with different thicknesses, the latter being elaborated with a suspension of $6 \mathrm{wt} . \%$ in solid content.

Figure 7 shows a picture of a fractured section of the duplex coating. It highlights the different scales of the elements forming the SPS and APS layers and also their different microstructures resulting, to a large extent, from the differences in the mechanisms controlling the flattening of the nano- and microdroplets onto the surface. The

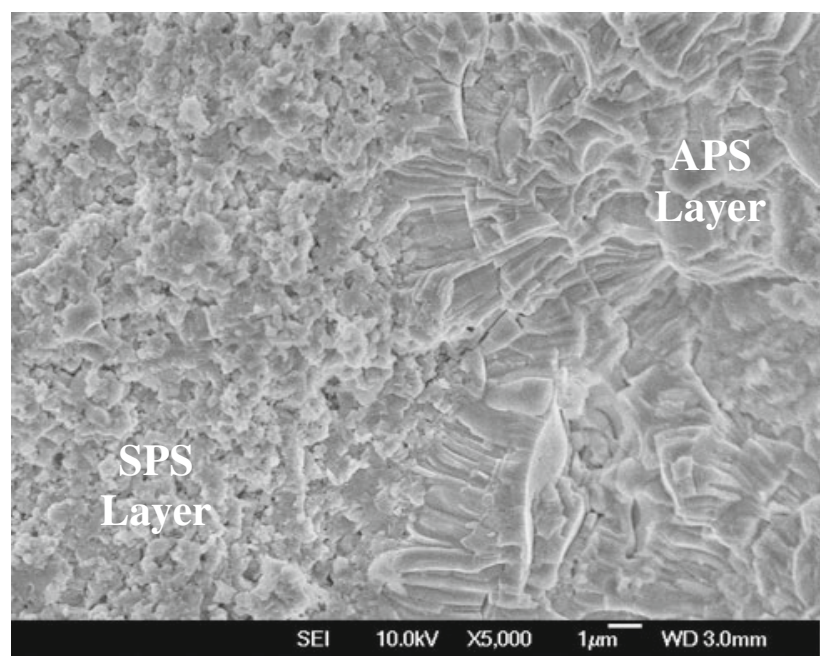

Fig. 7 Interface between the SPS layer (30 $\mu \mathrm{m}$ thick, 6 wt. \% of solid content in suspension) and APS layer (deposited with Ar- $\mathrm{H}_{2}$ plasma gas, see conditions in Table 1)

topcoat exhibited a columnar microstructure with the growth of columns between several splats. Even if the substrate was maintained at low temperature $\left(200{ }^{\circ} \mathrm{C}\right)$ during the deposition process, thanks to cryogenic cooling, the SPS layer acted as an insulating layer and prevented the rapid cooling of the solidifying splat and thus favored the columnar growth between splats. Figure 7 also shows some cracks or pores in the APS layer; they were parallel to the substrate and close to the SPS/APS interface.

The measured tensile bond strengths are shown in Fig. 8. The average values ranged between 12 and $24 \mathrm{MPa}$ depending on APS conditions and SPS layer thickness. The highest value was obtained for the APS layer deposited with the Ar- $\mathrm{H}_{2}$ plasma gas. Indeed, the $\mathrm{Ar}-\mathrm{H}_{2}-\mathrm{He}$ gas mixture made it possible to get more porous coating $(22 \%$ instead of $11 \%$ ) but to the detriment of the cohesion of the coating that was composed of molten and partially molten particles.

The values of the tensile bond strength of the duplex coatings are in the low range of the values found in the 


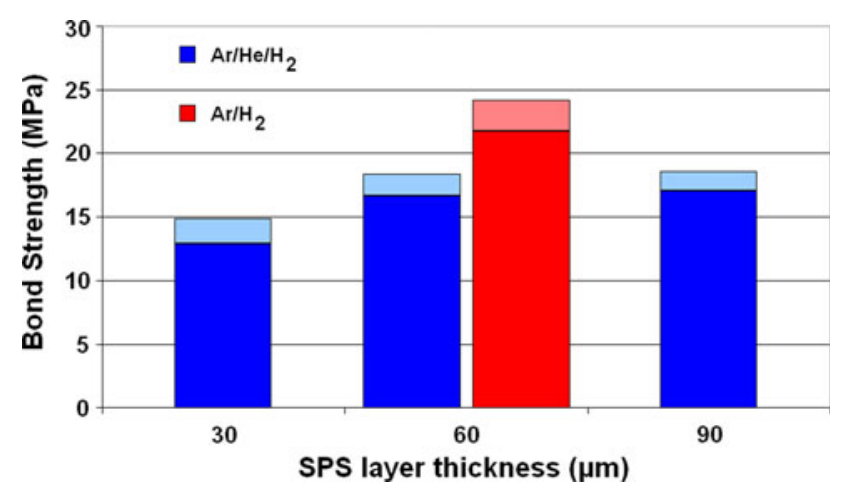

Fig. 8 Tensile bond strength of the duplex coating for various SPS layer thickness

literature for YSZ TBC with metal bondcoat that are generally between 20 and $40 \mathrm{MPa}$ (Ref 17).

The noticeable point in this study was the rather low dispersion in test measurements ( $<12 \%$ for five tests). Also, whatever the thickness of the SPS layer, the observation of the tensile test specimens showed that the fracture was located in the APS layer close to the interface between the SPS layer and the APS layer. This could be explained by a low quality of contact between the first layers of splats that composed of the APS layer and some cracks between these splats as it can be observed in Fig. 7 .

Higher tensile bond strength values were obtained for the APS deposited on the thicker $(60$ and $90 \mu \mathrm{m})$ SPS layers. It should also be noticed that, during APS deposition, the upper part of the SPS layer (3-4 $\mu$ m thick) was eroded at the beginning of the deposition process by the nonmolten and resolidified particles acting like grit-blasting. This was observed by comparing the thickness of the SPS bondcoat of the duplex coating and that of the SPS layer manufactured with the same spraying parameters. The impact of the micrometer particles onto the SPS layer surface could induce compressive stresses in the coating detrimental to the adhesion between the two YSZ layers.

The duplex bond strength could be increased by spraying the APS layer on the SPS layer as fast as possible after the deposition of the SPS layer and by maintaining the substrate at a higher temperature during deposition $\left(400{ }^{\circ} \mathrm{C}\right)$.

\section{Concluding Remarks}

A duplex coating of YSZ was directly made on smooth $(\mathrm{Ra} \sim 0.5 \mu \mathrm{m})$ and thin sheets of Haynes ${ }^{\circledR} 230$. It was composed of a nanostructured layer $<100 \mu \mathrm{m}$ thick and a microstructured layer about $500 \mu \mathrm{m}$ thick. The first layer was produced by SPS and the second by APS. This coating is intended to act as an insulating layer to protect various parts of the GFR nuclear system. The specifications for the application impose a high adhesion of the insulating coating on the Haynes ${ }^{\circledR}$ substrate. The nanostructured SPS layer should increase the adhesion of the YSZ APS coating on metal substrate and also help to relieve the strain in the duplex coating.

The adhesion properties of the SPS layer on Haynes ${ }^{\circledR} 230$ substrates were investigated by a VIC method that made it possible to compare the adhesion of the various coatings while the tensile bond strength of the duplex coating was measured by the ASTM-C-633 tensile adhesion test.

It was found that

- the SPS layer had good adhesive properties to the Haynes ${ }^{\circledR}$ substrate when the substrate temperature was at least equal to $400{ }^{\circ} \mathrm{C}$ during the deposition stage,

- the duplex coating had tensile bond strength ranging between 12 and $24 \mathrm{MPa}$ depending on the spraying conditions and SPS layer thickness, the highest value corresponding to the APS layer deposited with $\mathrm{Ar}-\mathrm{H}_{2}$ plasma gas,

- the failure of the duplex coating occurred in the APS coating close to the SPS/APS interface.

\section{References}

1. A Technology Roadmap for Generation IV Nuclear Energy Systems, US DOE Nuclear Energy Research Advisory Committee and the Generation IV International Forum, December 2002

2. R. Stainsby et al, Gas Cooled Fast Reactor Research and Development in the European Union, Sci. Technol. Nucl. Install. 2009, 2009, Article ID 238624

3. H. Liao, P. Vaslin, Y. Yang, and C. Coddet, Determination of Residual Stress Distribution from In Situ Curvature Measurements for Thermally Sprayed WC-Co Coatings, J. Therm. Spray Technol., 1997, 6(2), p 235-241

4. O. Racek, C.C. Berndt, D.N. Guru, and J. Heberlein, Nanostructured and Conventional YSZ Coatings Deposited Using APS and TTPR Techniques, Surf. and Coat. Tech., 2006, 201, p 338-346

5. R. Vert, C. Dublanche-Tixier, D. Chicot, E. Meillot, A. Vardelle, and G. Mariaux, Adhesion of YSZ Plasma Sprayed Coating on Low Roughness and Thin Substrates, Surf. and Coat. Tech., 2010, 205(4), p 999-1003

6. E. Meillot, R. Vert, C. Caruyer, D. Damiani, and M. Vardelle, Manufacturing Nanostructured YSZ Coatings by Suspension Plasma Spraying (SPS): Effect of Injection Parameters, J. Phys. $D, 2011, \mathbf{4 4}, 194008,8$ pp

7. S.H. Leigh and C.C. Berndt, A Test for Coating Adhesion on Flat Substrates-A Technical Note, J. Therm. Spray Technol., 1994, 3(2), p 184-190

8. R. Vert, X. Decoopman, I.C. Gruescu, E. Meillot, D. Chicot, A. Vardelle, and G. Mariaux, Adhesive and Cohesive Properties of Nanostructured $\mathrm{ZrO}_{2}$ Coatings by Vickers Indentation Cracking Technique, Thin Solid Film, 2011, 519, p 7789-7795

9. V. Debout, Ph.D. Thesis, in French, 2007, Limoges, University of Limoges, 285 pp, 2007. http://epublications.unilim.fr/theses/2007/ debout-vincent/debout-vincent.pdf

10. A. Bacciochini, J. Ilavsy, G. Montavon, A. Denoirjean, F. Ben-Ettouil, S. Valette, P. Fauchais, and K. Wittmann-Teneze, Quantification of Void Networks Architectures of Suspension Plasma Sprayed (SPS) Yttria Stabilized Zirconia (YSZ) Coatings Using Ultra-Small-Angle X-Ray Scattering (USAXS), Mater. Sci. Eng., A, 2010, 528, p 92-102

11. M.C. Biesinger, B.P. Payne, A.P. Grosvenor, L.W.M. Lau, A.R. Gerson, and R.St.C. Smart, Resolving Surface Chemical States in XPS Analysis of First Row Transition Metals, Oxides and Hydroxides: Cr, Mn, Fe, Co and Ni, Appl. Surf. Sci., 2011, 257(7), p 2717-2730 
12. S. Colin, E. Beche, R. Berjoan, H. Jolibois, and A. Chambaudet, An XPS and AES Study of the Free Corrosion of $\mathrm{Cu}-$, Ni- and Zn-Based Alloys in Synthetic Sweat, Corr. Sci., 1999, 41, p 10511065

13. S. Goutier, M. Vardelle, and P. Fauchais, Last Developments in Diagnostics to Follow Splats Formation During Plasma Spraying, J. Phys: Conf. Ser., 2011, 275, p 012003

14. M.C. Munoz, S. Gallego, J.I. Beltran, and J. Cerda, Adhesion at Metal-ZrO $\mathrm{Zr}_{2}$ Interfaces, Surf. Sci. Rep., 2006, 61, p 303-344
15. T. Chraska and A.H. King, Transmission Electron Microscopy Study of Rapid Solidification of Plasma Sprayed Zirconia, Thin Solid Films, 2001, 397, p 40-48

16. C. Delbos, J. Fazilleau, V. Rat, J.-F. Coudert, and P. Fauchais, Phenomena Involved in Suspension Plasma Spraying, PCPP, 2006, 26, p 393-414

17. C.R.C. Lima and J.M. Guilemany, Adhesion Improvement of Thermal Barrier Coatings with HVOF Thermally Sprayed Bond Coats, Surf. Coat. Technol., 2007, 201(8), p 4694-4701 